\title{
Notes on text
}

All citations from French published sources and from my fieldwork interviews have been translated from French to English. These translations are my own unless otherwise stated. For reasons of limited space, the original French text of these translated citations has not been provided. However, where French published sources are concerned, readers are directed to the original French text via the references. Elsewhere, some French words appear in the body of the text and if a translation is not given, please see the Glossary at the end of the book. 